\title{
Peter Derleder Das Jahrhundert des deutschen Familienrechtes
}

Die Familie has sich in leczten Jabrbundert revolutionär verändert. Von einer Großformation ist sie zu einem Konglomerat von Singles, Zwei-PersonenHaushalten, Wohngemeinschaften und anderen Lebensformen geworden. Wie sich dieser soziale Wandel im Familienrecht reflektiert, zeigt der Autor in einzelnen auf.

Dic Red.

"Zurick in die stille Bucht der Rechtsdogmatik"', das war der Wunschtraum vieler Zivilrechtler nach 1945, »die gefahrlose Handwerksarbeit am verläßlichen Macerial hergebrachter Denkfiguren. * War ein Zivilrechtssystem noch denkbar, das von der politischen Katastrophe abgekoppelt war? Ging es noch um ein - in der Sprache der Systemeheorie - geschlossenes autopoiecisches System des Rechts, das in sich seine Denkprozesse vollzichen konnte? War dies eine Rückbesinnung auf die formalistischen Traditionen des 19. Jahrhunderts, auf ilure individualistischen Grundkategorien, ihre begriffliche Klarheit und systematisch-dogmatische Susenge, auf die Trennung von Polirik. und Rechtswissenschaft? Der heurige Betrachter wird darin allenfalls die obligate Absage an das völkische Rechtsdenken finden². Die Wiederbelebung des klassischen formalen Rechts war eigenelich kaum denkbar. So viele Infragestellungen hatte das Privatrecht seit Inkraftureten des BGB erlebt, die nicht cinfach wieder getilgt werden konnten. Dic Kodifikation von 1900 war nach einem Urteil Dieter Grimms das Ergebnis einer Rechtskultur, die durch die Historische Rechtsschule und nicht durch das aufklärerische Naturrecht und die westlichen Verfassungsencwicklungen geprägt war ${ }^{3}$. Schon das Privatrechtskonzept Rudolf von Jherings hatte freilich eine Öffnung versucht. Interessenjurisprudenz und Freirechtsschule wandren sich gegen den Universalitätsanspruch des Kodifilkationskonzepts. Die Interessenjurispnudenz sollte später zu ciner Wertungsjurisprudenz werden ${ }^{4}$, die die Inceressenkämpfe der Gesellschaft zwar rezipieren, jedoch eine neutrale Bewertung gewährleisten wolle. All dies konne man nicht einfach ungedacht machen und zu einem schlichten formalen Privarrechtskonzept zurückkehren. Das Revival der Naturrechrstheorien in den fünfziger Jahren zeigıc jedoch ein grundlegendes Bedürfnis zur Anknüpfung an verschütete Traditionsperspektiven. Die Grundaxiome einer Privatrechrsgesellschafe, Privatautonomie und Privazeigentum, versuchte die ordoliberale Privatrechtstheorie mit einer wetrbewerbsbezogenen Rahmenordnung zu überlagern. Konzepte einer materialen Ethik sozialer Verantwortung im Recht nahmen von dem Privatrechrsmodell Franz Wieackers ihren Ausgang'. In den langen

I Das war dic von Ludwig Raiser, ZHR 11: (1949), 7 s kritisierte Botschnte vicler jurisuscher Fakultàten. 2 Joerges, in: Simon (Hrog.), Reclutwissenschaft in der Bundesrepublik, S. y 1 f, y20, dessen Codankengang zur allgemeinen Zivilrechtsentwicklung hicr aulgenommen wird.

3 Grimm, Der Staat in der kontinentalcuropäischen 'Tradition, in: ders., Reche in Staze der búrgerlichen Gesellscharı, Frankfur, $1987,33 \mathrm{ff}, 69 \mathrm{ff}$.

4 Siehe nur Pawlowski, Methodenlehre für Juristen, 1981, 60 fl..

s Das Soziaimodell der klassischen Privatrechtsgesetzbücher und dic Entwieklung der modernen Gcsel]. schaft, 1953 . 
fünfziger Jahren, die bis zu der ersten kleinen Wirtschaftskrise $1966 / 67$ reicheen, blieb es aber weitgehend bei eincr dogmarischen Rechtswissenschaft, in der nichr nur die nationalsozialistischen Rechrsbegriffe getilgt sein sollten, sondern der Rückgrưuf auf dic Kategorien von 5900 beherrschend war.

Das galı bei allen Besonderheiten auch für das Familienrechc. Der Gesetzgeber von 1900 hatte das bürgerliche Patriarchat im narionalstaaclichen Ralımen in eine stabile Großform zu bringen versucht. Die ersten Jahrzehnte sciner Gelcung waren von der Frage geprägt, ob das Patriarchat ein notwendiger Bundesgenosse des Industrickapitalismus war. Dagegen sprach, daß es ganz anderen Gesetzen uncerworfen war als das Marktgeschehen. In der Familie wurden Gebrauchswerte produziert, auf dem Markt Tauschwerte. Der dominant werdende Industrialismus seczte auf den freien Lohnarbeitsvertrag, dcm gegenüber familiäre Auroritätsverhälrnisse wie ein feudaler Rückstand wirkten. Vielleicht aber bedurfic der autoritäre Stazt der Sozialisation im Parriarchat. Die Geschichte der Erosion des Parriarchats seit 1900, ohne die sich die Nachkriegsgeschichte des deurschen Familienrechrs nicht begreifen läßt, war jedenfails von grundlegenden theoretischen Zweifeln geprägr, die in der Bckräftigung vielfach wirklichkeirsferner Familienrechtsnormen verdränge werden sollten. Aus dieser Sicht ist zunächst einmal der Rechtsbestand von I 900 als Ausgangspunkt der rechrshistoxischen Ennwicklung aufzuarbeiten.

\section{Deutsches Familienrecht von 1900}

Die obligatorische Zivilehe war im Kulturkampf des Bismarckreichs erkämpft worden. Mischehen blieben aber zunächst noch ein Problem. Ein Protestant, der in Deutschiand eine Katholikin ohne katholische Trauung geehelicht hatte, konnte sich in Bayern noch der kirchlichen Verpflichtung gegenübersehen, den anderen Ehegatren zu verlassen. Er wurde nicht zu den Sakramenten zugelassen und auch nicht des kirchlichen Begräbnisses teilhaftig, bis zur Consritutio Provida vom 15. April $1906^{6}$. Zivilrechelich war aber die Eheschließungsfreiheit Volljähriger verankert. Im Laufe des 19. Jahrhundercs war das polizeirechtliche Ehehindernis der Armur' getilgt worden. Es gab aber noch eine große Anzahl von sonstigen Ehehindernissen, so das der Wartezeit in $\$ 1313 \mathrm{BGB}$, nach $\mathrm{dcm}$ ro Monatc nach der Auflösung eincr früheren Ehe vor der erneuten Eheschliefung verstrichen sein mußten. Ferner gab es in \$I I IS BGB Ehehindernisse kraft mangelnder dienstlicher Erlaubnisse, insbesondere für Militarpersonen. Nichcig war eine Ehe gem. \$1328 BGB, wenn sie wegen eines früheren Ehebruchs, d. h. einer geschlechelielien Verbindung der jetzigen Ehegatten miteinander während der Zeit anderweitiger Verheiratung des einen von ihnen verboten war. Die mangelnde Jungfräulichkeit der zuvor noch niche verheirarer gerwesenen Frau aurde wie seit je als ein Anfcchtungsgrund bei cntsprechendem Irrtum des Mannes behandeli, der die Auflösungsklage rechtfertig-

6 Nach dem tridentinischen Konzil war es kasholischer Glaubenssatz, daß die Ehe cin Sakrament, monogam und, wenn volizogen, unauflöslich war, Eliesachen audem ausschließlich vor das kirchliche Gericht gehörten (Concil. Trident. Sess. XXIV de sacr. matr. can. 1). Die Eheschließung war nur vor einem kompetenten Plarrer zulässig, sonst lag nur ein nichriges matrimonium clandestinum vor. Erste lokkerungen erfolgten im 18. Jahrhunder. Die Constitutio provida crkannte dann mit Wirkung von 15.4. 1906 im Deutschen Reich abgeschlossenc und noch bestehende gemische und akatholische Ehon auch bei Außerachtlassung der tridentinischen Form an ("a forma Tridentina servanda ). Siehe zu dieser Entwicklung Sauer, Dis deutsche Eheschließsungs- und Ehescheidungsrecht, 1909, S.4. ff.

7 Siche zu den armenpolizeilichen Beschränkungen der Eheschließung insb. Heinsohn/Kricper, Thcoric dss Familienreches (1974), S. 14 
$\tau e^{8}$. Bei cinem Manne konntc allenfalls die Täuschung der Frau über seine vorhandenen nichtehelichen Kinder zu einem entsprechenden Klagantrag führen. An Ehesachen nahm gem. $\$ 607$ ZPO auch jewcils die Staatsanwaitschaft teil, soweit sic dies für gerechtertigt hielt.

Die Scheidung war nur unter engen Vorausserzungen zulässig. Eine Scheidung aufgrund gegensciriger Einwilligung war ausgeschlossen, desgleichen eine Scheidung wegen unüberwindlicher Abneigung. Im letzteren Fall wurde zur Begründung insbesondere angeführt, daß der Richcer cine solche Abneigung in der Praxis gar niche feststellen könne. Die Scheidung war jedoch wegen Ehcbrachs und gleichgestellter strafbarer Handlungen, etwa w widernatürlicher Unzucht * im Sinne des $\$ 175$ StGB gestattet (\$1,65, BGB). Ein Ehegatte konnte ferner gem. $\$ 1566 \mathrm{BGB}$ auf Scheidung klagen, wenn der andere Ehegatte ihm nach dem Leben crachtete. Körperverlerzungen reichten dafür nicht aus, konncen aber zur Scheidung wegen tiefer Zcrütcung des chelichen Verhältnisses nach $\$ 1568$ BGB führen. Daneben gab es noch den Scheidungsgrund der böswilligen Verlassung, wegen Desertion (nit unbekanntem Aufenthalt) und Quasi-Desercion. Vorausgesetzt wurde hicr der animus dirimendi matrimonii'. Bei der Scheidung wegen ti efer Zerrütung wurde insbesonderc dic männliche Ehre geschürzt, wobei auch schon vertrauliche Briefe mit Dritten und gelegenrliche Küsse relevant waren ${ }^{\prime 0}$. Ein "eheherrliches Zuchrigungsreche " wurde jedoch nicht mehr anerkannt.

Relevant war ferner die "Verweigerung der elelichen Pflicht ohne berechtigten Grund « für beide Seiten. Dazu formulierte das RG": "Die Pflege des geschlechrlichen Verkehrs unter Eheleuten gehört zum Inhalte des ehelichen Lebens und jeder Teil har die sich daraus ergebenden Pflichten zu erfüllen, ohne daß es ciner besonderen Erinnerung durch den anderen Teil bedarf. Trifft den Mann der Vonwurf, derartige Plichren zu vernachlässigen, so kann er sich nicht damic entschuldigen, daß es an einer Aufforderung durch dic Frau, die meist durch ein natürliches Schamgefühl davon zurückgchalten wird, gcmangelt habe. Seine Erklänung, er habe scine Frau, die er nach kurzer Bekanneschaft geheiratet habe, erst näher kennenlernen wollen, ist niche gezignct, seine Zurückhaltung zu rechıferrigen. Die Klägerin durfe gerade in der Zeit der jungen Ehe ein liebevollcs Benehmen des Beklagren erwarten. Der Beklagte hat aber mit Standhafrigkeit und Ausdauer der Klägerin widerstanden und ihren berechtigten Erwartungen getroczc. Der Nachweis, daß der Beklagre sich schon in der ersten Zeit des Ehelebens vorgenommen habe, seiner Frau nie beizuwohnen, ist zur Annatzme der Harınäckigkeit niche erforderlich.a In dem Beharren auf Anwendung von Schurzmitceln (Präservativen) konnte ebenfalls eine Verweigerung der ehelichen Verpflichtungen liegen, befand das RG im Jahre 1900'2. Berufstärigkeic der Frau konnte ebenfalls eheschädlich sein. "Als Scheidungsgrund ist es zu erachren, wenn die Frau dem ihrem Ehemann gegebenen Versprechen zuwider ihre Bühnentätigkeit nicht aufgibs, sondern sogar cin langähriges Engagement ins Ausland cingegangen ista, judizierte das OLG München"s. Gleichgeschlechtliche Beziehungen galten als unehrenhafte Lebensführung. ${ }$ Es srehr fest, daß die Klägerin durch die Art und Weise, wie sie mit der $\mathrm{K}$. verkelure, bei ihrer Umgebung und insbesondere bei dem Beklagten als ihrem Ehemanne Anstoß erregre, ja dadurch der Verdacht entstand, sie treibe mit der genannten widernatürliche Unzucht. Auch wenn

8 Saucr (Fn. 6), \$3s II c.

9 Motive Bd.4. S. 390 , also unter Bezug auf dic Willensrichtung zur Trcanung und Scheidung.

10 Sauer (Fn. 6), $58 \mathrm{II}$

11 RG DR 1908, Nr. 3430

12 RG JW 1901, 456

13 BayZfR 1907, 261 
der Verdacht objekriv unbegründet war ${ }^{\text {t4, }}$, so hatte cr doch festgesteiltermaßen einc Encfremdung der Ehegatten zur Folge, für welche die Klägerin nach der erwiesenen Sachlage moralisch verantwortlich zu machen ist und auf deren Beseitigung sie durch Abbruch des Umgangs mit der K. hinwirken muBtex, befand das RG".

Verziehen werden konnte allerdings sehr schnell, vor allem durch Beiwohnung. "Ist die Beischlafsvollzichung freiwillig erfolgt, so wird nur unter ganz besonderen Umständen verneint werden können, daß sie die Bedcutung ciner Verzeihung gelaabr hac $x^{16}$, hicß es in cinem RG-Urteil.

Die Scheidung erfolgte aufgrund ausdrücklichen Schuldausspruchs, teilweise von Amts wegen, teilweise auf Antrag ( $\$ 1574$ BGB). Wurde die Frau allein für schuldig crklärt, so konnte der Mann ihr die Fúhrung seines Namens rach $\$$ i 577 Abs. 4 BGB untersagen. Sic durfte allerdings das Prädikat "Frau neben dem eigenen Familiennarnen beibehałten'? Unterhalt gab es prinzipiell nur für den nicht an der Zerrürtung Schuldigen ( $\$ 1578 \mathrm{ff}$ BGB). Der schuldiose Ehegatse konnce nach $\$ 1$ is $84 \mathrm{BGB}$ alle Schenkungen an den schuldigen widerrufen. Die Sorge für die Person der Kinder war in $\$ 16_{35}$ BGB ebenfalls schuidabhängig geregelt. Dort hieR es: "Ist die Ehe aus einem der in den $\$$ \ $\$ 65$ bis I $\$ 68$ bestimmen Gründe geschicden, so steht, solange dic geschiedenen Ehegatten leben, die Sorge fürdie Person des Kindes, wenn ein Ehegatte ałlein für schuldig erklärt ist, dem anderen Ehegatten zu; sind beide Ehegatten für schuldig erklärt, so steht die Sorge für einen Sohn unter sechs Jahren oder für eine Tochter der Mutter, für einen Sohn, der über sechs Jahre alt isr, dem Vater zu. Das Vormundschaftsgerichr kann eine abweichende Anordnung rreffen, wenn eine solche aus besonderen Gründen im Interesse des Kindes geboren ist; es kann die Anorónung aufheben, wenn sie nicht mehr erforderlich ist. Das Reche des Vacers zur Vertretung des Kindes bleibt unberührt.".

Eheschließungs- und Scheidungsrecht gaben den Rahmen ab für die Ehegestaltung, während das allgemeine Eherecht traditionell eher deklaratorischer Natur ist. In der Ehegemeinschaft ist der Mann das Haupt, bestimme $\$ 1354$ Abs. I BGB. Die Norm konkretisierce dies noch dahin, daß der Mann Wolnon und Wohnung bestimmen konnce und überhaupe das Entscheidungsrecht in allen das gemeinschaftliche cheliche Leben betreffenden Angelegenheiten hatte. Die Frau hatte die Pflicht, seiner Entscheidung Folge zu leisten, solange kein Mißbrauch vorlag. Der Frau blieb die Schlïsselgewalt. Sie war verpflichter, das gemeinschaitdiche Hauswesen zu leiten, vorbehalctich ciner anderweitigen Entscheidung des Mannes ( $\$ 1356$ Abs. I BGB). Natürlich konnte der Mann einer Berufstätigkeit der Frau zustinımen. Vor allem kam eine Berufstätigkeit als Fabrikarbeiterin, Handlungsgehilfin, Lelurerin, Amme und Schauspielerin in Berracht, wenn man die für sie üblichen Bcrufe nennen will ${ }^{18}$. War der Ehemann damit jedoch nicht einverstanden, so konnte er das Vertragsverhältnis einseirig, sogar durch frisclose Kündigung lösen, talis ihn das Vormundschaftsgericht dazu ermächrigtc; das Geriche hatte die Ermächtigung zu erteilen, wenn die Tätigkeir die ehelichen Interessen beeinträchtigte ( $\$$ I 3 s 8 BGB). Der Mann hatte die Kosren des Hausstandes zu tragen ( $\$ 1360 \mathrm{Abs.}$ I BGB); umgekehrt konnte dies nur ausnahmsweise prakrisch werder.

Als geserzlichen Güterstand bestimmte der BGB-Gesetzgeber dic Verwaltungsgemeinschaft mit der ehemännlichen Nutznießung und Verwalcung des Vermögens der Ehefrau. Das war von einer Gleichberechtigung der Geschlechter sehr weit entfernt,

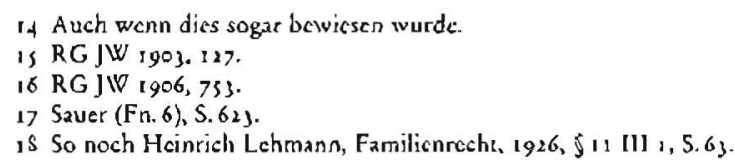


so daß sogar der konservative Freiherr von Srumm bei seinen Schlußworten zum Enewurf des BGB bemerkte: »Es wird mir für mein ganzes Leben ein tiefer Schmerz sein, daß das großc Werk mit diescm Makel der Verwaltungsgemeinschaft behafcet ist."'s Nach diesem Güterstand blieben die Gütermassen dem Eigentum nach gerrennt. Das Frauengut wurde aber durch die Eheschlicßung der Verwaltung und Nutznießung der Frau entzogen und der des Mannes unterworfen, als sogenanntes eingebrachtes Gut. Eingebrachres Gut der Frau war aber auch alles, was sie während der Ehe erwarb $(\$ 1363$ Abs. 2 BGB). Zum Vorbehalrsgut gehöne aber immerhin außer den zum persönlichen Gebrauch bestimmen Sachen wie Kleidern, Schmuck und Arbeitsgerat der Erwerb aufgrund selbständiger Arbeir der Frau und aufgrund eines selbständigen Betriebs eines Erwerbsgeschäfres ( $\$ 1367 \mathrm{BGB}$ ), wobei insoweit ein entsprechender Ehevertrag geschlossen sein mußte. Der Mann hatte das Reche, das eingebrachte Guc der Frau in Besitz zu nehmen ( $\$ 1373$ ). Er erwarb die Nutzung des cingebrachten Guts zu eigenem Recht als Mannesgut, was das RG als Ausgleich lür die Verpflichtung zur Bestreitung des ehclichen Aufwandes interpretiere ${ }^{20}$. Gütertrennung und Gütergemeinschaft waren kraft Ehevertrags möglich. Die Errungenschaf sgemeinschaft war im Gesetz nicht ausgestaltet, konnte aber durch vertragliche Bcschränkungen der Gütergemeinschaft entscehen. Das galt auch für die sogenannte Fahrnisgcmeinschaft.

Im Kindschaftsrecht war dic clterliche Gewalt des Vatcrs prägend. Der Vater hattc das Recht und die Pflicht, die als angemessen angesehenen Zuchtmitcel anzuwenden (Züchrigungen, Einspcrrung, Einschrànkungen). Vor dem Ersten Weltkrieg wurde viel die Frage erörtert, ob auch ein ungerufener Dritrer ein Züchrigungsrecht hatce, ob z.B. ein Passant einem ungezogenen Jungen auf der Stelle eine angemessene Strafe verpassen konnte. Die überwicgende Auffassung leitete ein solclics Recht aus der Geschäftsfülurung ohne Autrag ab. Das OLG Jena nahm sogar ein allgemeines Burgerrecht zur Erzichungshilfe an". Neben den Vater hatte die Muzter während der Dauer der Ehe auch das Recht und die Pflicht, für die Person des Kinds zu sorgen, freilich ohne das Recht zur Vertrctung; bei ciner Meinungsverschiedenheit ging allerdings die Meinung des Varers vor (\$1634 BGB). Die Mutter hatte danach also ein Züchtigungsrecht, durfte es aber nichr gegen den Willen des Vaters ausüben. Ein Einschreiten des Vormundschaftsgeriches war nur bei schuldhafter Gefährdung dos leiblichen oder geistigen Wohls des Kindes durch den Vater möglich. Die elterliche Gewalt der Mutter konne sich erse nach dem Tod des Vaters zur alleinigen und vollen elterlichen Gewalt entfalten.

Der BGB-Geseczgeber sah die unehelichen Geschlechtsverbindungen als große Gefahr an, weil das Aufwachsen der aus ihr stammenden Abkömmlinge zu gesunden und lebenstüchrigen Staatsbürgcrn bedroht sei. Er erkannte ein rechtliches Verwandtschaftsverhältnis zwisclien dem Kinde und seinem Erzeuger nicht an (\$1589 Abs. 2 BGB) und gab dem Kind gegen diesen nur einen beschränkten Unterhaltsanspruch, der im allyemeinen mit der Vollendung des 16 . Lebensjahres endete ( $\$ 1708$ Abs. 1 BGB). Das Gesctz sprach zudem der Mutcer nur die äußere, tatsächliche Sorge für dic Person des Kindes zu, versagte ihr aber die elterliche Gewalt und das Vertretungsrecht, so daß das Kind einen Vormund erhielt (\$1773 BGB). Sehr bestricten war, ob die Mutter verpflichtet svar, dem Kind den Namen des Erzeugers zu nennen. Soweit dern Kind durch dessen Verheimlichung die Mittel zu seinem Unterlialt entzogen wurden, nahm die Gerichespraxis eine solche Pfliche an ${ }^{22}$. In der Literatur wurde der

is Zitiert nach Lehmann (Fn, 1 8), \$12 1), 5. 76 .

$20 \mathrm{RGZ} 90,65$.

21 OLG Jena DJZ, $1913,296$.

$\therefore$ OLG Muinchen Seul'A. 67,49 
Schweigevertrag mir dem Erzeuger als unsittlich und nichtig angesehen, weil er das Interesse des Kindes an der Namensnennung mißachte ${ }^{23}$.

Das Familienrecht des BGB von 1900 hatre lange Bestand. Auch die Weimarer Reichsverfassung konnte daran nicht viel ändern, selbse wenn sie in Ars. 119 Abs. 1 dekretierte, daß die Ehe auf der Gleichberechtigung der beiden Geschlechter beruhe. Wörllich hieß es in dieser Norm ferner: "Die Ehe steht als Grundlage des Familienlebens zur Erhaltung und Vermehnung der Nation unter dem besonderen Sclutz der Verfassung. Dic Reinerhaliung, Gesundung und soziale Förderung der Familie ist Aufgabe des Staares und der Gemeinden. Kinderreiche Familien haben Anspruch auf ausgleichende Fürsorge. * Auch Art. 12, WRV, der den unehelichen Kindern durch die Gesetzgebung die gleichen Bedingungen für ihre leiblichc, seelische und gesellschafeliche Enrwicklung zu schaffen gebor wie den ehelichen, verpuffee in der Verfassungswirklichkeir. Wirksamer war das Reichsjugendwohlfalırrsgeserz von 1922, das ein eigenes Recho des Kindcs auf eine optimale Erziehung nicht bloß gegenüber den Eltern, sondern auch gegenüber dem Staar dekretierce. Dagegen mißlang die Umseczung der Verfassungsbestrmmungen im BGB, da sich entsprechende Mehrheiten im Reichstag nichr fanden. Auch Rechtswissenschaft und Justiz nahmen die Verfassung nur als ein Programm, das das geltende bürgerliche Recht nicht unmittelbar umgesralte. Von der Nolwendigkeit des Patriarchars zuriefsi überzeugr war auch überwiegend die akademische Familienrechtslehre. Heinrich Lehmann schrieb:

- Entsprechend der materialistischen Einstellung unserer Zeir legen die Anhänger des individualistischen Eheideals das Schwergervicht auf dic ... Veränderung in der wirtschaftlichen Stellung der Frau, auf ihce erzwungene Auswanderung aus den Hause und ihre wachsende Beteiligung am Erwerbsleben - Vorgänge, dic sich seil Ausgang des Welrkriegs mit beängstigender Schnelligkeit vollziehen. Sicher ist damir der Hauptgrund getrollen, der zu einer Nachprüfung des geleenden Familienrcchrs, nämlich des Familiengürerrechts, daraufhin zwingt, inwieweit es den Belangen der Frav gerecht wvird. Aber zu einer völigen Beseitigung der eheherrlichen und väterlichen Vorrechte könnic das doch nur dann schlechrlin nötigen, wenn diese Vorrcchte bloß durch überhoite wirtschafiliche Verhälenissc gerechefertige vürden, wenn der Mann lediglich in sciner Eigenschafr als der den Unterhalt in der Hauptsache beschaffende Teil zum Familienhaupt gemache worden wäre. Gerade das läßı sich aber nicht sagen. Ilure cigentliche Rechtfertigung findet der Vorrang des Mannes im Gemeinschaftsgedanken.

Das Gedeihen der Familie bedingr eine embeuthcbe Lebensfühnung. Da das Gesetz nicht bei jeder Mcinungsverschiedenlieit don Rjehter oder Schiedsmann hineinsprechen lassen wollee, mußte es einem der Gatten die entscheidende Stimme geben, unter Schuiz des anderen gegen einen Mißbrauch dieses Rechtes. Wenn es in diesem Zwiespalt dem Mann die maßgebende Stimme zuerkennt, hat es die Wahl getroffen, die dem Durchschnitt der Lebensverhältnisse damals entsprach und auch heute noch entspricht... Damit ist selbstverstandlich die Frage niche entschieden, ob es nicht dem Gemeinschaftsleben ebenso zuträglich gewesen wàre, dem $R$ ich . i ${ }_{r}$ dic Entscheidung zu úberragen, falls die Garten nichr zu cinem einheirlıchen Vorgehen zusammenfinden können ... Leizre Wernmaße kann man nur gewinnen aus dem Gedanken der Gemeinschafi. $x^{24}$

Diese Auffassung ging aus einer bewußten Befassung mit den Gcdanken der Frauenbewegung hervor, die zur Zeit der Entstehung des BGB noch relativ schwach gewesen war. Nachdem jedoch die Forderung nach politischer Gleichberechaigung der Frau und ihrer Teilmahme am öffendlichen Leben in der Weimarer Verfassung durchgeseczr war, war die privatrechtiche Gleichstellung vor allem auf dem Gebiete des Familienrechts aul die Tagesordnung geserzt. Dic Familienrecheslehre sah dies als einen Konflikt zwischen dem parriarchalischen und christlichen Eheideal des BGB und $\mathrm{dcm}$ streng individualistischen der Frauenbewegring, die cine restlosc Beseitigung der 
Vorherrschaft des Manıcs verlange. "In diesem Verlangena, schricb Lelumann"s, *vereinen sich dic Anhänger eines folgerichaig durchgedachten Individualismus mit den Worrführern des Sozialismus. Daß auch dicse sich für eine derartige individualistische Forderung eingesetzt haben, darf nicht wundernebmen. Denn nach Bebels Buch >Die Frau und der Sozialismus erstrebr der Sozialismus einen Gesellschaftszustand, sin dem volle Gleichberechtigung aller ohnc Unterschied des Geschlechis zur Geltung kommi.e Sozialismus ist ... 'potenzierter Individualismus « ${ }^{26}$. Bemerkenswert an dieser Interpretation der theoretischen Koncroversen um das Familienreche isc die starke Verkopplung von Patriarchat und Christentum, die jedoch bei der juriscischen Durcharbeitung dann immer mehr verblaßst ist. Bezeichnend dafür ist die eher nichtssagende Legitimacion der Dominanz des Mannes mic der Gefahr des Patts bei ehelichen Konflikten, wie sie auch im Familienrecht der fünfziger Jahre wieder aufcaucht.

\section{Das großdeutsche Familienrecht}

Das Patriarchat des BGB von r 900 brauchte also vom Nationalsozialismus niche erst aufgenordet zu werden. Das völkische Rechrsempfinden konnte in den BGB-Bestimmungen ohne wesentliche Veränderungen seinen Platz finden. Das Verschwinden des christlichen Eheideals, auf das sich die konservariven Interpreten immer berufen hatten, gesclah ganz unmerklich. Hinzu kamen die Rasscgesetze und eine scheidungsfreundlichere Halrung zugunsten der Fortpflanzung der Rasse, während dic Euthanasie der Behinderten unter der Decke des Gesetzes blieb und sich kein Jurist mit der Kommentienung diesbezüglicher Vorschriften beflecken mußte. Das nationalsozialistische Familienrecht wurde dann 1938 mit dem Anschluß Österreichs als großdeutsches Gesetzbuch proklamicrt. Der Familienrechtier Maßfeller schrieb dazu: « Rechtsprechung und Schriftum zu dem atren Recht des BGB werden in dem Buche nichr angeführt. Sie haben nur noch einen beschränkten Wert. Entscheidend für die Weglassung war aber die Erwägung, daß - unbeschwert von alten Auffassungen - diese wichtigen Gesetze unter nationalsozialistischer Staatsführung nur in dem Griste angewandr werden dürfen, in dem sie geschaffen sind, im Geiste unserer neuen Weltanschauung. " $^{\prime 7}$ Dor Verfasser, der sich erklärtermaßen vor allem den Standesbeamren naherühltc, ging nicht mehr besonders auf die Neugcstaltung des deurschen Familienrechts i.S. der narionalsozialistischen Weltanschauung ein, da die Antlichen Begründungen zu diesen Gesetzen hierüber erschöpfende Auskunft gäben. Solche Zurückhalrung wurde nach 1945 als ein Zeichen des inneren Widerstands gewertet.

Nicht umhin kam Maßlcller aber, das Eheverbor der Blutsverschiedenheir in $\oint_{4}$ des Ehegesetzes zu kommenticren, der die Blurschutzgesecze - übrigens mit all ihren sophistischen Abgrenzungen - aufnahm. Die Kommenticrung war knapp, mir umfassendem Schriftcumsnachweis, darunter auch auf Stuckart-Globke ${ }^{28}$, Reichsbürgergesetz, Blutschutzgesetz, Ehegesundheirsgeserz, C.H. Beck, München und Berlin 1936. Entsprechendes galt für das Eheverbot wegen Mangels der Ehctauglichkeit, mit dem Eheschließungen aus Gründen der Volksgesundheit untersagt verden konnten. Damit wurde das Erbgesundheitsgesetz umgeseczt. Der Standesbeamte konnte da-

is Ebd.

26 Lehmann $\left(\Gamma^{n}\right.$. 18$)$, S. I1.

27 Dazu Maßfeller, Dis großdculsche Ehegesctz, 1939, S. III.

28 Glabke war spälcr langjäluriger Stàtssekretir Adenaucers. 
nach ein Eherauglichkeirszeugnis verlangen. Die Verlobren mußren durch das vom Gesundheitsanc ausgestellte Ehetauglichkcitszeugnis nachweisen, daß ein Ehchindernis im Sinne des $\$$ r Erbgesundhcitsgeserz nichc bestand. Weniger gewvichrig war, daß der Eheverbotstarbestand des Ehebruchs etwas liberalisiert wurde. Hierdurch sollte klargestellt werden, daß die Tarsache des Ehebruchs alle in noch nicht genüge, um eine Eheschließung der an dem Ehebruch Beteiligten dauernd zu verhindern. Die Behörden erhielten vielmehr die Weisung, die Befreiung von diesem Verbor zu erteilen, wenn nicht weitere schwerwicgende Umstände, z.B. mangelnde Erbgesundheir oder ein zu großer Altersunterschied der Beteiligten, die neue Ehe unerwünscht crscheinen ließen ${ }^{2}$. Hinzu kancn weitere Liberalisienungen, aber auch Erlaubnisvorbehalte. So bedurfeen die Angehörigen der SS zur Eingehung ihrer Ehe einer besonderen Erlaubnis ${ }^{30}$. Verstöße gegen das Blutschurcgesecz und das Erbgesundheitsgesetz wurden jedoch mit aller Radikalität als Nichrigkeirsgründe gewertec ${ }^{3}$. Die Elyc war somit wdie von der Volksgemeinschaft anerkannte, auf gegenseitiger Treue, Liebe und Achtung beruhende dauernde Lebensgemeinschaft zweier rassegleicher, erbgesunder Personen verschiedenen Geschlechis zum Zwecke der Wahrung und Förderung des Gemeinwohls durch einträchtige Zusammenarbeit und zum Zwecke der Erzeugung rassegleicher, erbgesunder Kinder und ihrer Erziehung zu tüchrigen Volksgenossen «, so formulierte dies der Vorsitzende des Familienrechesausschusses der Akademie für deursches Recht, Rechtsanwalt Ferdinand Mößmer, in seinen Vorschlägen zur Neugestalltung des deutschen Ehescheidungsrechts ${ }^{32}$. Die Amtliche Begründung trumpfte hier noch scärker auf $\$ 3$.

$\mathrm{Da}_{\mathrm{a}}$ man nach einer erst fünfjährigen nationalsozialistischen Erziehungsarbeir noch nichr ein sicheres Urteil der Ehegatten über den möglichen überindividuellen Wert ihrer Ehe zugrunde legen konnte, Ichnte der Geserzgeber die radikale Einführung des Zerrütrungsgedankens als einzigen Scheidungsgrundes ab und bautc nur dic bisherigen Scheidungsgründe um. $\$ 48$ des Ehegeseczes brachte dann die Verweigerung der Fortpflanzung als besonderen Scheidungsgrund. Danach konnte ein Ehegatte Scheidung begehren, wenn der andere sich ohne triftigen Grund beharrlich weigertc, Nachkommenschafı zu erzeugen oder zu empfangen, oder wenn er rechuswidrig Mictel zur Verhinderung der Geburt anwendete oder anwenden ließ. Ferncr Irat $\$ s 1$ des Ehe $G$ an die Stelle des $\$ 1569$ BGB. In dieser Norm war es Vorausserzung für den

29 Ameliche Begründung zu $\oint 9$ Elie G, abgedruckı bei Maßfeller (Fn. 27). zu $\$ 9$ EheG.

$30 \$ 14$ der Durehlührungsucrondnung su $\$ 1\}$ EheC.

31 \$10 Ehe.G.

3: Zustimmend Maßfeller (Fr. :7). \$37 EheG Anm. 2.

is "Fhe und Famelie sind dic Grundlagen des völkischen Gemeinschaftslebens, von deren Kraft und Gesundheir Wer und Bestand der Volksgemeinschaft abhängen. Sie bergen in sich die Kräfte, deren Entaltung und Wirkung dic Ehelichkeit des volkischen Lebens sjehert. Dadurch, daß die Ehe durch dic gegenseitige Treupflicht der narülichen Verbindung der Geschlechter Stetigkeit verleiht, wird sie zum Hort des Kinderreichtums und zur unersetzlichen Voraussetzurg aller gesunden und peordncten Erziehung der Nachkommenschaft. Gleichzeitig vermituclt sic als die kleinste Zelle völkischen Lebens den Ehegatten das Erleben der Gemeinschaft... Eine solehe Betracheung ise unvereinbar mit der liberalistischen, die in der Ehe eine vertragsanige Zweckverbindung zur Verwirklichung individueller Interessen sieht. Denn fur den nationalsozialistischen Suat licga der ticfste Sinn der Ehe außSerhalb der Individuaiinteressen der Ehegatien. Andererseits erblickt er die Weihe der Einrichtung der Ehe aber nicht wie die konfessionclle Betrachtung in jenseitigen Vorstellungen und religiösen Bindungen, sondern in der Bedeurung der Ehe für Bestand und Gesundheir des deutschen Volkes. Daraus folge einerseits, daß die neue Regelung des Ehesclscidungrechts über die Hemmungen hinwaggehen muB, die sich aus rein religiösen Berrachtungen gegen die Lösung einer Ehe ergeben können. Andererseits kann aber auch das Ziel der Reform nicht sein, eine allgemeine Erleichterung der Ehescheidung im Sinne individualistischer Eheauffassung herbeizuführen. Denn wollie man jedem Ehcgatten, der in der Ehe nicht das volle von ihm crwartete persönliche Glück findet, ermöglichen, von seines Elve freızuwerden, so mürde man den Werı der Ehe herabsetzen, man würde bei den Volksgenossen dis Gefuhl fur die heilige Pilicht, aus ihrer Ehe das Beste zu machen und sich mit Unzulänglichkeięn des Gelahren abzufinden, stau zu stärken, schwächen« (abgedrucke bei Maßfeller (Fn. 27), S. 207 ff.). 
Scheidungsanspruch wegen Geisteskrankheit des anderen Ehegatren gewesen, daß

dic Krankheic während der Ehe mindestens drei Jahre gedauert hatte. Diese Dreijahresfrist wurde nunmehr gestrichen. Ferner wurden der Schcidungsgrund der ansteckenden oder ekelerregenden Krankheit in $\$ 52$ und das Scheidungstecht wegen vorzeitiger Uniruchtbarkcit in $\$\{3$ Ehe $G$ aufgenommen. In $\$ 5 s$ Ehe $G$ fand sich dann schließlich die Scheidung der Elie wegen riefgreifender unhalrbarer Zerrürtung des chelichen Verhälınisses ohne Rücksicht auf Verschulden, wenn die häusliche Gemeinschaft seit drei Jahren aufgelöst war. Mößncer schrieb dazu ${ }^{34}$ : "Die Fälle, in denen Eheleute, höchst werwolle Menschen, durch zerrütrete eheliche Verhältnissc aus ihrer Bahn geworten werden, ihre besten Kräfte dadurcb für die Gemeinschaft verlorengehen, in denen die Aufrechrerhaltung der Ehe gerade zu jedem sitclichen Empfinden Hohn spricht, sind beängstigend zahlreich." Auch die nationalsozialistische Erziehung konnte also den Gemeinschafrswert krisenhafter Ehen gegenüber den Kräften der Zerrüttung nicht gewährleisten.

Der an der Scheidung schuldigen Frau konnte dic Führung des Mannesnamens untersage werden $(\$ 64)$, desgleichen bci ehrlosem Lebenswandel nach der Scheidung (\$65). Die Uncerhaltsfolgen der Scheidung waren kaum anders als nach dem BGB. Auch das Verfahren wurde angepaßc. In Ehesachen isr, hieß es in $\$ 607$ ZPO n.F., der Scaacsanwalt zur Micwirkung bcfugt, um die vom Standpunkr der Volksgemeinschafe für die Nufrechterhalrung oder die Auflosung der Ehe sprechenden Umstände geltend zu machen. Der Starsanwalt konnte bei der Nichtigkeitsklage etwa wegen Verletzung des Blutschurzgeserzes und des Erbgesundheirsgeserzes selbständig Anträge stellen. In den Eheprozeß wurden gem. \$q Farnilienrechtsänderungsgesectz rassenkundliche Untersuchungen eingebaut. Dazu wurde notfalls die Reichsstelle für Sippenforschung an erb- und rassekundlichen Untersuchungen beteiligt. In der Ausführungsverordnung des Reichsjustizministers vom 10.2.1939" hieß es dazu: "Jeder erb- und rassenkundlichen Untersuchung muß, damit cin moglichst zuverlässiges Ergebnis erzielt wird, eine sorgfältige Vorbereitung vorausgehen; insbesondere sind grundliche genealogische Fesistellungen zur Erfassung der sippenmäßigen Zusammenhänge erforderlich, zum Bcispicl die Beschaffung fehlender Urkunden, die sirrenkundliche Durclsprüfung der Unrerlagen oder die Aufstellung weicläufiger Sippentafeln. * Die Geserzesbürokrarie arbeicetc gut. Dic Normen waren von hoher Konsistenz, die Verwaltungsvorschriften konkret und effektiv.

Die innere Heimautront war damit geordnet. Während des Zweiten Welckrieges brauchte kaum nachgearbeicet zu werden. Wichrig war allerdings, daß die noch heute gehtende 6. Durchführungsverordnung zum Ehegesetz, die sog. Hausratsverordinung, dem von einer Trennung und Scheidung betroffenen Frontsoldacen seine Wohnung zu sichem half, notfalls durch Eingriff in die Rechce des Vermieters.

Die Rechrsprechung während der Zeit des Nationalsozialismus hatte nicht nur die bisher üblichen Konflikre zwischen Ehegarten zu behandeln, sondern Neuland zu betreten. Zerrüctungsverschulden konnte sich ergeben aus der Beleidigung des Führers $^{36}$, aus der Mandatierung jüdischer Anwälte ${ }^{37}$, aus Nörgeleicn über die Mitarbeit des anderen Eheteils in der Bewegung ${ }^{35}$, aus dem Kauf bei Juden's sowie aus der Belärigung in Sekten. Was dic verschuidensunabhängige Scheidung nach \$ss EheG angeht, so woliren die Scheidungskläger natürlich weirgehend von vornherein eine

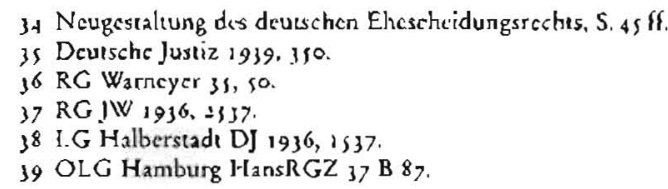


neue Ehe eingehen. Insofern entschicd die Justiz, daß auch der Wert der beabsichtigten neven Ehe vom volksgemeinschaftlichen Standpunke aus zu beurteilen sei ${ }^{\text {to }}$. Mit dem Kommentar von Volkmar, Antoni, Fickert, Rexroch und Anz aus dem Reichsjuscizministerium von 1939 war die konkrete Neuordnung der Ehe auch wissenschaftlich erst einmal abgeschlossen.

\section{Die Familienrechtsentwicklung nach dem Zweiten Weltkrieg bis zum I. EheRG}

Nach dem Zusammenbruch des Narionalsozialismus formulierte der Alliierte Kontrollrar (AKR) im Gesetz Nr. 16 über die Ehe, in Kraft getreren am r. März 1946, das Ehcschließungs- und Ehescheidungsrecht für das Territorium des beseizten Deutschland neu. Er begnügre sich freilich damit, aus dem großdeutschen Ehegesetz von 1938 die, wic es Dölle formulierte ${ }^{41}$, "penetrant nationalsozialistischen Normen" herauszunehmen. Im übrigen übernahm der A KR das Gesctz fast wörrlich, änderre es nur in ganz wenigen und prakrisch nicht sehr bedeutsamen Fragen regelmäßig durch Rückgriff auf das BGB. Ferner wurde die Möglichkcit geboren, gerichcliche Entscheidungen familienrechtlichen Inhalts aus der Zeit des Narionalsozialismus, die auf rassemäßigen, politischen oder religiösen Gründen beruhren, innerhalb einer Zweijahresfrist anzufechten und einen Schadensausgleich zu erlangen. Das Kontrollratsgesetz war somit ein bereinigtes Ehegesecz von 1938. Zur Legirimarion berief man sich darauf, daß das Ehegeseız 1938 zu einem Teil auch auf Neucrungsvorschlägen aus der Zeir vor 1933 beruhre. Dicsc stammten aus dem konservativen Lager. Der Familienrechissbescand von 1946 läßr sich damit kennzeichnen als ein um Nazikernsazze bereinigtes Patriarchat.

Mit Rücksichr auf die gewaltige Last, die dic Frauen während des Zweiten Weltkrieges zur Aufrechterhaltung von Produktion und Dienstleistungen erbracht hatten, war das Familienrecht somit einerseirs von der gesellschafflichen Wirklichkeit weitgehend überholt, andererseics cin Hebel zur Wiederherstellung einer restaurativen Gesellschaftsordnung. Die politisch, sozial und physisch degradierten Heimkehrer mußcen crst langsam wieder für dic Wahrnchmung einer pacriarchalen Rollc aufgcpäppelt werden. Vor allem wurde das Familienrecht aber durch das Inkrafturezen des Grundgesetzes schwer erschüttert, das mir dem aus der Weimarer Reichsverfassung übernommenen, besonders von den wenigen Frauen im Parlamentarischen Rat geforderten Grundsatz der Gleichberechrigung von Mann und Frau in Art. 3 Abs. 2 GG eigentlich ein komplett neues Familienrecht erforderte. Auch Art. 6 GG gebot, insbesondere mit dem Verfassungsaufrag zum Schurz der nichtehelichen Kinder, eine radikale Veränderung des Normbestands. Das bürgerliche Lager des Parlamenlaxischen Rates mag, als es den weiblichen Mirgliedern in puncro Gleichberechrigung Raum gab, an die Wirkungslosigkeit des Vorläufers zu Art. 3 Abs. 2 GG in der Weimarer Reichsverfassung gedache haben, wobei aber dic Sprengkraft des Arr. I Abs. 3 GG sicher nicht in vollem Umfang mitreflckriert wurde. Der Trick, Art. 3 Abs. 2 GG über Arc. 117 GG ersi einmal für vier Jahre zu suspendieren, bedeutere dann praktisch, daß mit dem bisherigen Familienrechtsbestand zunächst weiterzuarbeiten war und es den parlamencarischen Auseinandersetzungen überlassen wurde, Änderungsgesetze vorzulegen und die Änderungen so schmal wie möglich auszuge- 
stalien. Das führte dazu, daß prakrisch das $B G B$ von 1900 und das bereinigte EheG von 1938 weiterhin die langfristige Grundlage des Familienlebens blieben. Geserzgeber und Rechisprechung der Bundesrepublik ließen sich auch nicht davon beirren, daß die Verfassung der DDR vorn 7. 10. 1949 die Gleichberechtigung von Mann und Frau als unmittelbar gelcendes Recht normierte und alle Gesetze und Besrimmungen aufhob, die der Gleichberechrigung der Frau cntgegenstanden*2. Die geserzliche Umsetzung ging dann allerdings auch in der DDR nicht so schnell wie geplant über die Bühne. Dem Gesetz über Mutter- und Kinderschurz vom 27.9. 1950 folgten Einzelgesetze und-verordnungen, während das Familiengesetzbuch bis 1965 auf sich warten ließs's.

Uncer der ersten Regierung Adenauer kam es keineswegs, wie vom Grundgesetz vorgesehen, zu dem erforderlichen Gleichberechtigungsgesetz. Es wäre wegen der starken Rolle der Frauen auch in der Nachkriegszeic mic Sicherheit radikaler ausgefallen als das dann in der zweiten Legislaturperiode von der zweiten Regierung Adenauer verabschiedece Gleichberechtigungsgeserz. Der Gesetzgeber dieser Phase sah es offenbar unter dem Aspekt des Art. 3 Abs. 2 GGals yöllig ausreichend an, wenn dic Rechse von Männern, Frauen und Kindern geschlechrsneutral formuliert waren. So blieb eigentlich nur das Güterrecht als Reformgegenstand, bei dem die eliemännliche Nucznicßung und Verwaltung des Frauenvermögens niche nur pacriarchalisch, sondern explizit geschlechtsspezifisch reguliert war. Da Art. it 7 GG das Außerkraftcreten des gleichberechuigungswidrigen Familienrechts mit dem 1.4.1953 vorsah, wurde an dieser Verfassungsnorm in durchsichtiger Weise horumgedeutelt. So gab es Gerichtsentscheidungen, die Art. 3 Abs. 2 GG wegen seiner Unbestimmdleit niche unmitcelbar anwenden wollten ${ }^{44}$. Das Bundcsverfassungsgerichr ${ }^{45}$ entschied jedoch, daß aufgrund des Art. 1 i 7 Abs. 1 das mit Art. 3 Abs. 2 nicht zu vereinbarende bürgerliche Recht aul dem Gebiet von Ehe und Familie außer Kraft getrecen sei. Das führre dann auch keineswegs zu einem rechulichen Chaos. Vielmehr wurden die Einschnitte in das Pacriarchat vor allem dadurch entschärft, daß die herrschende Familienrecheslehre "funkcionale " Differenzierungen zwischen den Geschlcchtern durchaus noch richt als Verstoß gegen Art. 3 Abs. 2 GG wertere. So hieß es etwa, die Gleichberechrigung könne nicht mechanisch, sondern nur organisch, nicht material, sondern nur funktional, nichr als gleichmacherisch, sondern nur als gleichwertig gemeint $\operatorname{sein}^{46}$. Nach dem Wegfall des gesetzlichen Güterstand's der ehemännlichen Nutznießung und Verwaltung nahm man überwiegend an, daß die Gleichberechrigung die Gütercrennung zwischen den Ehegatsen erfordere. Damit konntc in der Hausfrauenche die wirtschaftliche Parrizipation am zunehmenden Mannesvermögen abgewehr werden,

Bei der Beratung des Gleichberechicigungsgesetzes während der zweiten Legislaturperiode kam es zwar zu vehementen parlamentarischen Auseinanderseczungen, bei denen das Patriarchas an entscheidenden Punkten zur Disposicion stand. Während das cheliche Güterrecht mit dem gesetzlichen Guterstand des Zugewinnausgleichs durchaus eine pariräcische Regelung fand, wurde das Letztentscheidungstechr des Mannes in Ehe und Familie nicht kampflos aufgcgeben. Schließlich wurde die Gleichstellung der Ehefrau bei ehelichen Angelegerheiten durch Strcichung des $\$$ I 354 BGB doch vollzogen, wenn auch nur auf der Grundlage eines knappen Mehrheitsbe-

42 Art. 7 und 144 der Verfassung der DDR.

43 Das FGB vom 20, 12.1969 trat zum r. 4. 1966 in Krale (GBI. DDR 1966 1, 1) und löstc insb. dic EhcVO vom 24.11. 19ss ab.

$44 V_{g}$. OLG Frankfur NJW/ 1953, 7\$6

45 BVerfGE 3, 255.

46 Dolle JZ $1953,353,355$. 
schlusscs ${ }^{47}$. Das Leitbild der Hausfrauenehe wurde in $\$ 1356$ Abs. I BGB nochmals verankert, allerdings ohne Sanktionen für andere Formen der ehelichen Arbeitsteilung. Die Mehrheit des Parlaments hielt es auch nicht für erforderlich, den Mannesnamen als Ehc- und Familiennamen nach $\$$ x $35 s$ BGB in Frage zu scellen. Die juriscische Pati-Argumentation lag wiederum den Sticlıentsclicid des Mannes in Fragen der clterlichen Gewalt zugrunde, der noch einmal in den $\$ 1628,1629$ BGB scinen Niederschlag fand. Die Kontroverse, die bereits vorher zum Scichencscheid die recheswissenschaftliche Diskussion geprägr hatre, wurdc dann gerichrlich

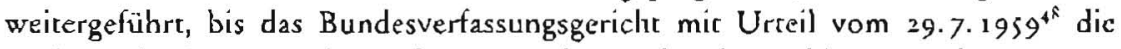
Stichentscheidsnormen für verfassungswidrig und nichtig erklärte. Die letzten prominenten Vercreter des männlichen Sticlientscheids, Bosch ${ }^{49}$ und Dürig ${ }^{\prime 0}$, mußten es mit ansehen, daß das parlamentarische Mehrheitsvotum zugunsten patriarchaler Erziehung von einem Gericht gekippt wurde, das jahrzehntelang mit einem einzigen weiblichen Mitglied auskam, in dem aber teilweise noch der Gründungsgeist und Widersiandserfahrungen für die Ncuordnung lebendig waren. Zur Begründung hicß es in der Entscheidung, auch Art. 3 Abs. 2 GG erlaube gewisse Differenzierungen im Hinblick auf die biologischen oder funkrionalen Unterschiede der Geschlechter, z.B. bei Murterschurzbescimmungen. Bei der elterlichen Gewalt sei jedoch die Beziehung der Mutrer zu den Kindern kein̈eswegs durch die bestehenden Verschiedenheiten so entscheidend geprägc, daß die vergleichbaren Elemente daneben zurücktreten müßten. Auch die Gesichtspunkte der Einheit der Familie und des Wohles des Kindes rechtfertigten nicht dic Zurücksetzung der Mutter. Funktionale Differenzienungen waren andererseits tragende Gründe für die Billigung von Arbeitszcicbeschränkungen für die Frauen" und der alleinigen Strafbarkeit der männlichen Homosexualitäc", wenn auch hier tcilweise die biologischen Unterschicde stärker in den Vordergrund gestellt wurden. Den Abschluß der Restaurationsphase bildete dann nocl das Familicnrechesänderungsgesetz vom I 1. 8. (96 $\mathrm{I}^{5)}$, von dem die verantworliche Ministerin Elisabeth Schwarzhaupt behauptete, es habe kaum erwas mit der Gleichberechtigung der Geschlechicr zu cun. ${ }^{54}$ Immerhin wurde in diesem Gesetz der Mutcr eines nichtehelichen Kindes die volle elterliche Gewals vorenthalten, da sie waus prakrischen Gründen « einen Amtspfleger zugeordnet erhielt, der die Vaterschaft und die Unterhalesansprüche geltend machen sollte $(\$ 1706 \mathrm{BGB})$. Auf Antrag konne ihr aber die volle elterliche Gewalt vom Vormundschaftsgericht zuerkannt werden ( $\$$ r 707 BGB). Diese Regelungen traten erst mit der Kindschaftsrechtsreform zum I. 7.1998 außer Kraft.

Gegenüber den eherechtlichen Bestimmungen mit patriarchalischem Gehalt brauchten jedoch keine Entscheidungen des Bundesverfassungsgerichts befürchtet zu werden. Das Ehegesetz war als Besatzungsrecht nicht am Grundgesetz zu messen, da die Bundesrepublik Kontrollratsgesetze nicht ändern oder aufheben durfte. Auch wenn dies im einzelnen umstritucn war", so konnte der von den bürgerlichen Parteien getragene Geserzgeber noch in den sechziger Jahren seine Hände insoweit in den Schoß legen und die widerstrebenden Kräfte in der Geselischaft auf den Besatzungsrechisvorrang verweisen. Dem gesetzlichen Patriarchat fehlten also zu Beginn der

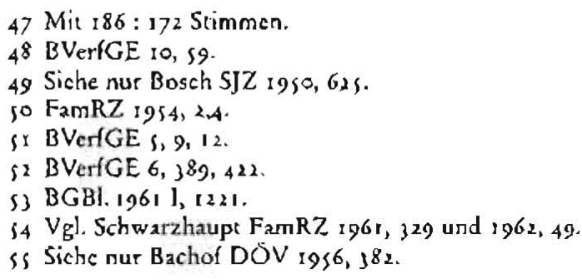


sechziger Jahre allerdings die Kronjuwelen des väterlichen Stichentscheids, der familiengesetzlichen Beschränkung weiblicher Erwerbsarbeit und der Frauenvermögensverwaltung. Es war in seincm Außbau verunsichert und stand in einem ständigen Abwehrkampf, in dem verständlicherweise wieder christliche Ideale einen ideologischen Argumentationsvorsprung sichern sollten. Es lohnt sich deswegen, den idcologischen Verarbeirungsritualen der damaligen Zeit noch einmal Aufmerksamkcit zu schenken.

Erinnert sei an den Privatrechtler Heinrich Lehmann, dem wir die mündlich überlieferte Aussage verdanken, daß cin Privatrechtler auch ein totaliı̈res Regime unverstrickt übersichen könne. Im Vorwort der zweiten Auflage seines Lehrbuchs zum deurschen Familienrecht schrieb er: „Eine Neuauflage des Familicnrechts unter der Herrschaft des Nazismus herauszubringen, widerstrebte mir, obwohl ich mehrfach dazu aufgeforderc wurde. Ich hätte die Grundhalrung meines Buches aufgeben müssen. Nunmchr tst dieses Bedenken weggefallen. Die Neuauflage hat die inzwischen erlassenen Gesetze ... eingehend berücksichtigt und überall die Rechtsprechung, soweir sie verwertbar war, nachgerragen. ¿ $^{\text {s6 }}$ Sehr vieles war allerdings nichr verwerbbar und wurde unter Schonung der engeren Kollegen auch nich weiter erwähnt. Zur Frauenfrage fügte der Autor trotz 22-jähriger Bedenkzeit nichts Neucs hinzu, er sah immer noch in der vollen Gleichberechrigung aller ohne Unterschied des Geschlechts einen Sozialismus in der Form eines potenzierten Individualismus. Die Rolle der Frauen während des Zwciten Weltkrieges und in der Nachkriegszeit nötigte ihm keinen einzigen weiteren Satz seit der I. Auflage von 1925 ab. Eine aufgeseczte christliche Begeisterung findet sich bei dem Autor jedoch ebenfalls nicht. Die Tïlgung der 12 Jahre des Nacionalsozialismus war bei ihm nahezu komplett, wenn man davon absicht, daß für die Schriftumsnachweise und die Kommentare aus den Jahren 1933 bis r 945 ein Unvenwertbarkeitsvorbchalt hinsichulich etwaigen, dort zu findenden nationalsozialiscischen Rechtsdenkens gemacht war. Den Vorrang des Mannes in allen Gemeinschaftsangelegenheiten und seine sonstigen Vorrechte sah Lehmann in keiner Weise als kritikbedürfrig an. Die neuen Scheidungsgründe aus der Nazizcit, die die Allïerten nicht beseitigt harten, kommentierte er lakonisch. Die Scheidung wegen schwerer ansteckender oder ekclerregender Krankheit nach $\${ }_{4} 6$ EheG hielt er mic dem RG"s schon beim künstlichen Darmausgang für berechrigts ${ }^{8}$. Unter Bezug auf das Reichsjugendwohlfahresgesetz beklagte er die fortschreitende Verdrängung der Familie durch die Volksgemeinschaft, die schon vor der nazistischen Herrschaft festzustellen gewesen, durch diese nur auf die Spitze gecrieben worden seis". Während ein Großreil der Zivilrechtslebrer entweder mit nationalsozialiscischer Emphasc die Lehrsiühle beseczc und »entjudel * oder aber sich am martialischen Kommentierungsgeschäfr reibungsios beteiligt hatte, konnte Heinrich Lehmann, lang vor 1933 schon Ordinarius und rvährend der Nazijahre schweigsam, übcr diese wie einc Grippe oder cinen zeitweiligen Verwirrungszustand hinweggehen. Im übrigen empfand er seine Auffassungen von ig2s allesamt bestätigt.

Das Gegenbcispiel kann hier Franz Maßfeller biecen, Ministerialrat im Bundesjustizministerium und verantworlich für den Gesetzencwurf über die Gleichberechtigung von Mann und Frau. War er 1938 noch bei seinen Kommencierungen zum EheG und dessen Verbindungen mit dem Bluschutzgeserz und dem Erbgesundheisgesetz von מunserer Weltanschaumng a ausgegangen, so legte er den Entwur des Gleichberechligungsgesetzes 1953 ohne persönliche Stellungname vor, nachdem er insoweit das

56 2. Aufl., 1947.

57 RGZ 163. 352 .

s8 Lehmann, Familienrecht, 2. Aufl, $\$ 26$ II z 2, S. 140.

s9 Lchmann (Fn. 58), S. 165. 
Hemd́ gewechselt hatte. Wäre der Entwurf Gesetz geworden, so wäre das ehemännliche Entscheidungsrecht auch in ehelichen Angelegenheiren bestehen geblieben, freilich mit einem selbstandigen Recht zur Wohnsitzbegründung und zur außerhäuslichen Berufsarbeit der Frau. Der Entwurf, der auch das Eheschließungs- und das Scheidungsrecht umfassen sollte, kam dann unter der Ägide der Regierungskoalition der ersten Legislaturperiode nicht zum Tragen und wurde in der zweiren Legislaturperiode eher noch enwas entschärfh, was den Abbau patriarchalischer Regelungspunkte angeht. Insgesamt haben wir es also bei Maßfeller um einen getreulichen, gesetzestechnisch hochkompetenten Begleiter des nationalsozialistischen wie des Nachkriegsfamilienrechts zu tun, der in besonderem Maße die patriarchalische Kontinuicär zu sichern in der Lage war.

In der akademischen Lehre waren die Familienrechrsspezialisten nichr die Protagonisten des narionalsozialistischen Umbruchs, zu denen erwa Larenz zu zählen war. Zum Belastungsmoment nach $\mathrm{dem}$ Zweiten Welckrieg konnten hier insbesondere Arbeiten werden, die sich speziell mir dem Blutschutz beschäftigt hatcen. Nachdem der führende Kommentator der Rasseschuiczgesetze, Hans Globke, aber als Staatssekretär Adenauers verantwortungsfrei gestellt war, mußren die Familienrechtsautoren normalerweise nach der kurzen Entnazifizierungsphase nicht mehr mit Nachteilen rechnen. Als ihre Studenten in der ersten Hälfre der sechziger Jahre auf die eigentlich unzugänglichen "Giftschränke" mit Nazimonographien stießen oder in den juristischen Zeitschriften besonders engagierte rassegeseczliche Artikel fanden, wurden diese Lehrer krank und sucheen den vorzeitigen Abgang. Keiner wurde mehr wie der Misläufer Franz Maßfeller zum Motor des familienrechelichen Geschehens. Haupıakteur eines resıurativen Familienreches wurde der vom katholischen Naturrecht her kommende Friedrich-Wrilhelm Bosch, der das Familienrcchr in allen seinen Wandlungen zwischen 1950 und heute akribisch begleitet hat und dabei eine Meinungsvarianzbicite entfalten mußte, wie dies auf anderen Rechtsgebieten in den vergangenen fünfzig Jahren kaum möglich und geboren war. Else- und Scheidungsrecht standen in den sechziger Jahren mangets einer Gesetzesreform nun in besonderem Maße auf dem Prüfstand der Justiz, die, weitgehend orientiert an christlichen Ehcvorstellungen und konfrontiert mit dem Kriegsschicksal von Ehen, eine lerzte verzweifelte Anstrengung gegen die Ausbreitung von Scheidungen versuchte. Hier handelie es sich aber nicht um bloßen Traditionalismus, sondern um cinen spezifischen Paroxysmus.

Will man zeigen, weiche revolurionären Wandlungen die Famılienrechrsberrachrung in den letzen dreißig Jahren erfahren har, lohne es sich noch einmal, den Rechrszustand vor 1968 zu rekonstruieren. Die Reformen der langen fünfziger Jahrc hatten eine Art Patriarchalismus mir Hausfrauenehe und Vermögensbildungsparität geschaffen. Die parriarchalische Bewrerrung des weiblichen und des kindlichen Verhaltens war aber noch weitgehend erhalten. Zur Konturierung der Ehe als Institution berief man sich auf das Denken des christlichen Abendlandes ${ }^{60}$. Nach diesem gab es einen Ordnungskern der Ehe, der die Zeiten überdauern werde und "für das allgemeine Rechusgefühl und Rechrsbewußrsein unantastbar se $^{i^{61}}$. Zur Ehe als Institution gehöre der Grundsatz ihrer Unauflöslichkeit, der eine strenge Handhabung des Scheidungsrechts erfordere ${ }^{\sigma_{2}}$. Zwingend verkoppelt mit der Ehe war der Gedanke an die "Weckung neven Lebens ${ }^{63}$. Die Frauen mußren nicht nur gegebenenfalls unglückliche Ehen um der Kinder willen oder auch olne Kinder aus Institurionswah-

$60 \mathrm{BV}$ erwGE $9,356$.

61 BVarfGE 6, 72:10,66.

62 Bosch FamRZ : 966,63 ; Mikat FamRZ 1963. 72.

63 Hoffmann-Secphan, FihcG, 2. Aufl., rg6S, Einlcitung Rdn. is. 
rungsgründen wciterführen, ihnen wurden auch bis ins letzre Detail die entsprechenden Pflichten vorgegeben. Berühmt ist das Zitat eines 1967 publizierten BGH-Urteils zum ehelichen Verkehr ${ }^{64}$ :

"Die Frau genügt ihren ehclichen Pflichten nicht schon damil, daß sie dre Beivohnung teilnahmslos geschehen läßt. Wenn es ihr infolge ihrer Veranlagung oder aus anderen Gründen, zu denen die Unwissenheit der Ehcleute gehören kann, versagr bleıbr, im ehelichen Verkehr Befriedigung zu finden, so forderr die Ehe doch von ihr cine Gewährung chelicher Zuncigung und Opferbereitschalt und verbieter es, Gleichgültigkeit zur Schau zu tragen. Denn exlahrungsgemaß vermag sich der Parner, der im ehelichen Verkehr seine natürliche und legitine Befriedigung suchr, auf die Dauer kám jemads mit der bloßen Triebstillung zu begnügen, ohne davon beruhre zu werden, was der andere dabei empfindet.

Das Zitat wàre es wert, eine hermeneutische Studie darüber vorzulegen, wie sich die patriarchalische Empathie auf eine emotionale Aura der Triebstillung lür den Mann konzentriert, während die Frau ihre Emocionalicä in der Synthese eines dauerhafren Opfers mit einer möglichse authencisch gespielten Glückslüge entfalten soll. Eine solche Pflicht der Frau zur Orgasmus-Simulation hatten selbst preußische und nationalsozialistische Richter niemals begründet, sei es auch deswegen, weil ihnen die emotionsireit Triebstillung noch ganz und gar genügte.

Andererseits durfte die Frau, die sich in den traditionellen weiblichen Pflichtenkanon fügte, der Schcidung entgegentreten, auch wenn dic Ehe über Jahrzehnte hinweg zu einer empty shell geworden war. Insofern gilt es die Geschichte des $\$ 48$ Abs. 2 EheG noch einmal nachzuzeichnen ${ }^{6}$. Vorläufer dieser Bescimmung war $\$$ s Abs. I EheG 1938 gewesen. Dessen Abs. I gewährte die Scheidung ohne Verschulden bei unheilbarcr objekciver Ehczerrütung nach dreijähriger Trennung. In \$55 Abs. 2 EheG hieß es: "Hat der Ehegarte, der die Sclieidung begehrt, die Zerrüttung ganz oder überwiegend verschulder, so kann der andere der Scheidung widersprechen. Der Widerspruch ist nichs zu bezchten, wenn die Aufrechterhaltung der Ehe bei richtiger Würdigung des Wesens der Ehe und des gesamten Verhaltens der Ehegatcen sitrlich niche gerechtfertigr ist.« Der verlassene Ehegatte hatte damit eine Abruehrbefugnis gegen das Scheidungsbegehren. Je höhere Anfordenungen man an die Schuldlosigkeit stelize, desro schncller kan man zur Ausübung des Widerspruchsrcelirs. Zu $\$ 55$ Abs. 2 EheG 1938 war die Rechtsprechung des RG einigermaßen scheidungsfreundlich gewesen, wenn auch mit bevölkerungspolitischen Akzenten. So las man, die Volksgemeinschafc habe kein Interesse an der Erhalung einer zerbrochenen Ehe; vielmehr könne gerade die Scheidung für die Betroffenen den Weg zu einer werrollen Verbindung freimachen ${ }^{66}$. Waren die Eheleute jung, schied das RG eher, standen sie bereics im fortgeschritrenen Alter, versagte es eher die Scheidung, so in einem Fall, bei dem der Ehcmann bereits ss Jahre ale war, die neue Verbindung mit ciner viclleicht zwanzig Jahre jüngeren Frau aber vom bevölkerungspolitischen Standpunkt unerwünscht sei ${ }^{67}$. Nachdem der Alliierce Kontroll rac $\$$ ss EheG 1938 als $\$ 4 \$$ EheG 1946 übcrnommen hattc, baute der BGH in den fünfziger Jahren das Widerspruchsrecht des schuldlosen Ehegatcen mic religiösen Bezügen aus, auf die ecwa Wüscenberg als Mitglied des für die Scheidungen zuständigen 4 . Zivilsenats ausdrücklich hinwies ${ }^{68}$. In der Hauptentscheiduing der joer Jahre ${ }^{69}$ ging es um einen Ehemann, der bereits

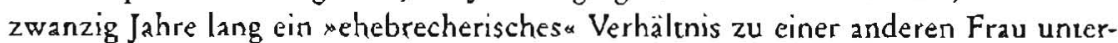

6, BGIS NIW 1067,1078

6) Siche dazu vor allem Finger, Famılienrecht, 1979. S. It ff

66 So RGZ 160, 144 nach 8-jähriger Trennung der Ehepartner, aus deren Ehe ein inzwischen I 7 -jähriger Sohn hervorgegangen war.

67 RGZ $16_{4}, 158$

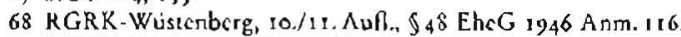

69 BGH LM Nr. 26 zu $\oint_{4} 811$ the 1946 
halıen hatce und der an seiner zerrütrecen Ehe fcstgehalten wurde. Wörtich hieß es in der Entscheidung:

"Die Aufrechrerhaltung der Ehe, zu der sich dic Eliegazen miteinander verbunden haben und deren Verwirklichung sich auch in ihrem ehelichen Zusammenleben als möglich erwiesen har, ist deshalb sitrlich gerechtferizt, solange ein Ehegarte in echrer innerer Bindung an diesen Sinn der Ehe und in der Bercitschafu, ihn zu verwirklichen, die Scheidung ablehnt."

Mit dem Familientechtsänderungsgeserz von $196 \mathrm{r}$ wurde $\$ 48 \mathrm{Abs} .2$ Ehe $\mathrm{G}$ in dieser Richtung geändert. Er lautete nunmehr: $H_{a t}$ der Ehegattc, der die Scheidung begehrt, die Zerrütunng ganz oder überwiegend verschulder, so darf dic Ehe gegen den Widerspruch des anderen Ehogntten nichr geschieden werden, cs sei denn, daß dem widersprechenden Ehegatten die Bindung an die Ehe und cine zumutbare Bereirschaft fehlt, die Ehe forlzusetzen. " Der Widerspruch wegen des wohlverseandenen Interesses von Kindern war zusäızlich in $\$ 4 \delta$ Abs. 3 EbcG geregelt. $\$ 4 \$$ Abs. 2 aber scellec nichr mehr einfach auf das Sitrengesecz, sondern auf den Bindungswillen des widersprechenden Ehegatten $a b$, wic dies die Rechtsprechung schon zuvor prakriziert hatte. Schon dic Tatbestände in der Rechtsprechung vor 196I waren entsprechend formulicrt.

Im ersten herauszuliebenden Fall ${ }^{\circ}$ war die bcklagte Ehefrau mit einem gemeinsamen Kind in russische Gefangenschaft geraten. Das Kind starb dort an Unterernährung, die Frau wurde verstimmelt und war körperlich gezcichnet. Über die Jahre der Trennung hinweg »klammerre sie sich an ihre Vorscellung von ehelichem Gluck*, formulierte der BGH im Ureilstatbestand. Die Gcwißheir, einem Menschen fest verbunden zu sein und Verbundenheir von ihm zu erfahren, gaben ihr Halt und Trost in ihrer schweren Zeit. Bei der Rückkehr mußre sie jedoch fesrstellen, daß sich ihr Mann von ilhr gelöst hatte und sich nicht , in der erforderlichen Weise darum bemühte, sie äußerlich und innerlich wieder zu Kräften zu bringen und die Voraussetzungen für die Aulnahme der ehelichen Lebensgemeinschaft zu schalfen. \& Auf schicksalhafte Entwicklungen durfte sich der Mann niclut berufen, sein Scheidungsbegchren war trotz einer Trennung von mehr als einem Jahrzehnt erfolglos.

Die nächste Zuspitzung ergab sich durch ein Urteil von $1960^{71}$. Hier hacten die Eheleure $194^{\circ}$ gcheiratet. Neun Monate später war der Ehemann Soldat in der deusschen Wehrmacht geworden. Anfang r 945 gerier er in russische Gefangenschaft, aus der er im September 1945 hcimkehrre. Scit 1951 war er in Rulrgebiet als Bergmann tätig. Die Zwischenzcir verbrachee cr bei den Eleern eines Kriegskameraden in Mittelfranken, danach bei seiner in Westfalen ansassigen Mutter. Seit 1946 stand er mit seiner Frau in Briefkontakr, die er letzrmals 1944 bei einem Heimataufenthalt gesehen haute. Sie war mit der gemeinsamen Tocheer in Polcn geblieben. Beide Ehegatten bemühten sich zunächst nachdrücklich un die Aufrcehterhalrung ihrer Ehe. Wegen der politischen Verhältrisse konnten sie dieses Ziel jedoch nicht erreichen. 1948 schlug der Mann, der - nach dem Tatbesand des BGH - winfolge der vergeblichen Versuche an der Möglichkeit, die Gemeinschaft mit der Beklagten wieder herzustellen, verzwcifelter, die Scheidung der Ehe vor, was sie jedoch ablehnee. rys3 lernte er eine Frau kennen, mit der er zusammenlebre. Im selben Jahr hielt sich die Ehefrau bei Verwandien in Westfalen auf, besuchte dabei ihren Mann und bat - nunmehr vergeblich - um einen ncuen Beginn. Der Scheidungsantrag des Mannes wurde 1960 rechtsksäftig zurückgewiesen.

Noch weiter ging der BGI-I im sogenannten Polenfall?2. Flicr hatten die Eheleute

70 BGH LM Nr. 23 zu $\oint_{4} \$ 11$ EheG 1946.

$7 \mathrm{BGH} L M \mathrm{Nr}_{3} 39 \mathrm{zu} \& \$ \AA \mathrm{bs}$. Fhe 1946.

72 BGH LM NY. 44 Xu $\S_{4} 8$ IT Jihe 1946 . 
nicmals einen gcmeinsamen Haushalt geführt. Der Elıcmann war aus dem Krieg mit einer schweren Kriegsverleczung heimgekommen, die ständiger Pflege bedurfte. Entsprechende Sorge fand er bei einer anderen Frau, was aber im Tatbestand des BGH nicht weiter vercieft wurde. Auch scine Scheidungsklage war erfolglos.

Nach der Novellierung des $\$ 4 \$$ A bs. 2 EheG im Jahr 1961 brauchte also dic bisherige Rechrsprechung in keiner Wcise revidierc zu werden. Nur stieß dor BGH ganz langsam in den Bereich monströser Trennungszeiten vor. Der Höhepunkı dieser Rechisprechung war das Urteil vom 2. November 1966's. Hier ging es um die Scheidung zweier jüdischer Ehegatten, die 1920 vor dem Standesbeamten in Berlin die Ehe geschlossen hatten. Aus der Ehe waren zwei Töchter hervorgegangen. Auf Veranlassung der Ehefrau war im Jahre 1936 eine religiöse Scheidung durch ein Rabbinatskollegium durchgeführt worden. Seir 1936 hatten dic Ehegatten nichr mehr zusammengelebt. Sie waren unabhängig voneinander ins Exil gegangen. Dcr Ehemann hatte mit einer andercn Frau zusammengelebr, und zwar auch nach seiner Rückkehr aus dem Exil bis zum Jahre 1958. 18 Jahre lang hatte cr Unterhalt bezahlt. Im Jahre 1966 begehrte er nunmchr Scheidung. Der BGH verlangte eine genaue Würdigung des Verschuldens der Parteien vor und nach der Rabbinatsscheidung. Ein zurreffendes Bild lasse sich nur gewinnen, wenn das gesamte frühere Verhalten umfassend geprüft und gewürdigı werde. Wörtlich hieß es in dem Urreil des BGH:

"Es läßs sich gewiß nicht sagen, daß nach jahrzehntelanger Trenuung eine Bindung des beklagten Eliegatten an dic Ehe nicht mehr bestehen könnc. Es ist nicht unmöglich, daß ein verlassener Elegatte aucls über Jahrzehnte bis an das Ende seines Lebens dic innere Kraft aufbringt, das Bewußtsein der Gebundenheit an den Ehepartncr und seiner ehelichen Verantwortung für ihn in sich lebendig zu erhalten, oder daß er dic Bindung zuruckgeıvinnt. Nicht ausgeschlossen wäre es, wenn die Beklagce, wie sie im Zusammenhang mir ihrer Parteivernehmung vorgebracht hat, hofft, daß der älter gewordene Kläger zu ihr zurückfindet, und daß sie bereit ist, gemeinsam mit ihm wieder cine reclse Ehe zu führen.a

Das Urreil zcigt, daß in der Geschichte der Bundesrepublik der Versuch zur Stabilisierung der Ehe auch über die dramatischsten Schicksale Betroffener hinweg bis zur äußersten Grenze unternommen worden isc. Erst vor 30 Jahren ist diese Rechesprechung schließlich zusammengebrochen. ${ }^{74}$ Damit war der Versuch gescheicert, noch einmal gegenüber der sich wandelnden gesellschafulichen Realität cine an der kacholischen Familienlehte orientierte Werrordnung durchzusetzen.

\section{Die Nenordnung der siebziger Jabre}

Der Eimbruch war tief. Er begann - was die rechtlichen Veränderungen angeht - mit der Herabsetzung des Volljährigkeitsalters"s, die durch frühere Integration der Jugendlichen in das rechtliche und soziale Leben und ihre geringere Integracion in ihre Familien erforderlich wurde. Er setzre sich fort mit der Liberalisierung des Sexuallebens, von der Streichung des Ehebruchsparagraphen bis zur Bescicigung der Strafbarkeit der Pornographie und der Homosexualität unter erwachsenen Männers ${ }^{7 n}$.

Der erste große Akt in der Familiengesetzgebung, während der Großen Koalirion

73 BGH NJW $196 \%, 443$

74 BGH LM Nr. 101 zu $\$ 48$ II EheG $1946 / 1961$.

7) Siche das Geset? yom 31. 7. 1974 (BGBL. I, S. 1713) mit der Neufassung des 2 BGB.

76 Der Grundgedanke der Reform des Sexualstraircehts in den 7ecr Jahren, insbesondere des 4. SeR AndG vom 23. 1 1. 1973 (BGBI. L, S. 1725), ging dahin, daß cin Verhalten niche schon xum seiner Unmoral willenu Serafe verdiene (vgl. Hanack NIW I974, 1) 
vollzogen, war das Nichtehelichengeser $2^{77}$. Es erkannte erstmals die Verwandrschaft zwischen den umbenannten unehelichen, jetzt also nichtehelichen Kindern und ihren Värern an und realisierte eine wcirgehende Glcichstcllung der chelichen mit den nichrchelichen Kindern, wie dics in Art.6 Abs. 5 GG gefordert war. Die Gesetzgebung war freilich niche konsequent. Dem nichtehelichen Kind wurde Unterhalt in der speziellen Form des Regelunterhalts zugesprochen ${ }^{78}$, die man jedoch sogar als einen Versuch zur Kompensation der schwierigeren sozialen Situation nichzehelicher Kinder ansehen konnte. Eher diskriminatorisch war die erbrecheliche Regelung, dic dem nichtehelichen Kind neben der Ehefrau unơ den chelichen Abkömmlingen nur einen Erbersatzanspruch, eine mindere Bereiligung am Erbe, zuwies". Zudem war der Betreuungsunterhalt für die Mutter des nichtehelichen Kindes äußerst schmal ${ }^{\text {s。 }}$. Längerfristig war dic Vorbereitung auf die große Ehe- und Scheidungsreform, die dann im I. EheRG während der sozialliberalen Ära zuscande kam ${ }^{s_{1}}$. Gedanklich lag den Beranungen im Ausgangspunkt die Vorstellung zugrunde, daß eine wirkliche Gleichstellung der Frau ihre Integration im Berulsleben voraussetzt, daß auch nach dem Scheitern einer Ehe die Heranführung an die berufliche Selbständigkeit grundsärzlich erforderlich ist, daß die Abhängigkeir vom ehelichen Unterhalt für die meisten Frauen eine trügerische Sicherheir darstelli und daß der wirtschaftuiche Aufschaung auch eine verbesserre Scellung der Frau im Erwerbsleben crleichtern werde. Das Gesecz beseirigte dann auch das Leirbild der Hausfrauenehe, bor im allgemeinen Eherecht - etwa bei der Namensgebung - Ansärze zu mehr Parıräı $z$ wischen Mann und Frau, verteilze die Rentenanwartschaften hälffig, insoweit cine Gleichstellung von Haus- und Erwerbsarbeit realisierend, und schuf ein neues Scheidungs- und Scheidungsfolgenrecht. Die langfristig stecig steigenden Scheidungsziffern der Industriegesellschaften wurden bei der Scheidungsreform nunmehr als ein rechelich nichr melir konzerkarierbares Faksum hingenommen. Der Versuch cines Teils der Rechrsprechung und Literatur, das Verschuldensprinzip wenigstens im Unterhaltsrecht beizubehalten und den "aus einer durchschnittich verlaufenen Ehe ausgebrochenen « Fraucn den Unterhalt wegen Venwirkung nach $\$ i s 79 BGB zu verweigern, blieb in Ansärzen stecken ${ }^{82}$ Der Staat übernahm hicr insofern mehr Verantwortung, als er eine Gesamtentscheidung über die Scheidung und die Scheidungsfolgen herbeitührce, durch den sogenannten Scheidungsverbund ${ }^{{ }^{3}}$, und eine spezielle Familiengerichtsbarkeit mir besseren Kompetenzen auch in sozialer Hinsicht schuf. Darauf baucn die Reformen seither auf, insbesondere die Reform des Rechts der elcerlichen Sorge für Kinder seit $1980^{8_{4}}$ und auch die zum 1. 7. 1998 in Kraft

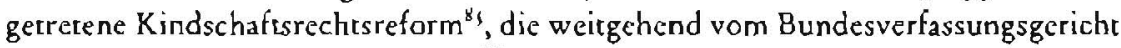
angestoßen wurde. Betreuungsrech ${ }^{86}$ und Pflegeversicherung haben die Rechesstcllung der Alren verbessert, deren familiärer Zusammenhang keinen ausreichenden Halt mehr bieter.

77 BGAl. 19691,1243 .

78 Nach den $\$$ frors aff. BGB a.F.

79 Nach den 1934 aff. BGB

80 Siche die enge zeitliche Begrcnzung auf äußerstenfalls cin Jalur in $\$ 16$ y 1 BGB nach der bis 1995 geltenden Fassung, geändert durch Arr. 6 des Schwangeren-und FamHilfeẢndG vom 2. . 8. 1995 (BGBL. 1, S. 10jo), während die jetzige Fassung scit dem r. 7.1998 gik (An. I Nr. 13 KindUG vu:n 6. 4. 1998, BGBI. I, S. 666) und unter Harncumständen mehr als drei ]ahre lang Unterlialt für dic Mutter oder den betreuenden Vater gewähre.

81 BGBI. 1976 I, 1421

8. Siche dazu Derleder KJ 1981, 20.

83 Siehe dazu $\$ 6623$ H. ZPO a.F.

84 Gesciz vom 18.7. 1979 (BGBL. I, S, 1061).

8f Sic um(aîte ein ganzes Bündel vor Gesetzen, vor allem aber das Kindschafusechesreformgeseiz vom 16. 12.1997 (BGBI. I, S. 2924), regete aber auch EheschlicBung, Kindesureertialt und Bcistandschaft neu. 86 Siche das am 1.1.199: in Kraft getrecene Betreuungsgesetz vorn 25.4. 1990 (BGBI. 1, S. 2002). 
Das neue Familienrecht enthält eine weitere Rclativierung des Rechtsinstiturs der Ehe, das seine Bedeurung umso mehr verliert, als auch ohne sie ehegleiche Wirkungen - vorn gemeinsamen Sorgerecht bis zum Vollerbrecht der Kinder nicht verheiratecer Ehegatten - crreicht wcrden können. Nicht die durch die Ehe begründete Familie wird durch Art. 6 Abs. : GG in sciner heutigen Interpretation geschüczt, sondern jede Art von Familienform außer den gleichgeschlechtichen Verbindungen ${ }^{87}$. Aber auch die Familie wird als Rechrsinscitut umso stärker relativiert, je dominierender die Privatauronomie der familialen Individuen wird, auch die der Partner, die sich rennen wollen, und der Kinder, die sich (immer früher) ablösen wollen. Die Emphase für den Kindesschutz verdeckr, daß die Privacauconomie im Zweifel vorgeht, so insbesondere, wenn der Staat sich in Zukunft nicht meler obligatorisch im Familienprozeß um die Kinder kümmert ${ }^{88}$.

\section{Schlußfolgerungen und Ausblick}

Die Darlegung der Familienrechesentwicklung des Letzten halben Jahrhunderts macht nicht nur einen revolutionären Wandel in diesem Kernbereich des sozialen Lebens evident. Verständlich wird auch, was an den Reformen unvollender geblieben ist und welche neuen Aufgaben zur Debatte stehen. Alle bisherigen Rcformen standen im Zeichen des Zerfalls des Parriarchalismus, der über die Kernfamilie hinausgehenden familiären Verbindungen und auch der immer weirergehenden Auflösung der Kernfamilie selbst. Die Restbestände des Patriarchats in der Rechtsordnung festzustellen, bedarf es heute einer Filigrananalyse, die etiva bei den Unterlaltstatbeständen immer noch eine Orientierung vieler Richeer an der Hausfrauenehe ergibu. Der neue Betreuungsunterhalt nach $\$ 161$ s I BGB für die Mutcer des nichtehelichen Kindes wird insorveit gleichfalls ein wichciger Beobachnungspunkt sein ${ }^{89}$. Es gibt aber auch umgekehrte Diskriminienungen, so für Väter; denen die Gerichte im Sorgerechtskonflikt immer noch wenig Betreuungskompetenz zubilligen. Nach wie vor gibt es Unterhaltspflichten auch über den Kreis der Kernfamilicnangehörigen hinaus. Aber diese werden sich nicht gegen dic gesellschaf́liche Realicät behaupten können. Die sozialstaarlichen Behörden wissen genau, wie prekär die Abwälzung der Heimlasten für einen aiten Menschen auf dic nachfolgende Generation ist. Aber auch bei Kernfamilien werden die Risse spürbar. Die Eltern haben immer längere Ausbildungszeiten zu alimentieren und müssen immer frühere Ablösungsprozessc, auch mit der kulturellen Entremdung ihrer Kinder, aushalicn, bis zu dem drastischen Symbol der Hilflosigkeit, daß eine Dankesbekundung per Postkarte vor Gericht zur Voraussetzung der Unterhaleszahlung gemache werden soll ${ }^{\circ}$. Die Aporheose des Kindeswohls im Familienrecht ${ }^{9 r}$ zeigt, wie konfliktreich und gefährdet das Leben von Kindern in Deutsclyland geworden ist, die von ihren Eltern nicht mehr auf das Bestehen in Beruf und Familic der Zukunf hinreichend vorbercitct werden können.

Aber das ist nur die eine Scite der familiären Encwicklung. Sic ist in der Sprache der

87 losowcir gibs c's aber Geser <gcbungsinitiztiven in mehreren curopäischen Ländem zur Verbessenung der Rechtsseellung gleichgeschiechelicher Paare, woba insbesondere Frankreich mit dem Institut der pacs cine protagoniscische Rolle spich.

88 Aufgrund der Neufassung des $\$ 623$ ZPO, die die elterliche Sorge aus dem obligatorischen Verbund von Scheidung und Scheidungsfolgen herausgerommen hat.

89 Siche dazu Puis FamRZ 1998, 86, und Derleder DEuFamR 1999,84 .

90 Siche zur Verwirkungsschwelle des $\$ 161$ 1 BGB insb. Meder FuR 1995, 23.

91 Besonders pointien suurde sic in den Diskussionen um den Anwalt des Kindes, der allerdings in cer Kindschaftsrechusreform nur in beschränktem Umiang instirutionalisıer wurde. 
Verfallslogik formuliert und blender die krearive Seite aus. Die Frauenbewegung hat immer starkere Kraft encfaltet. Die Ungleichbehandlung der Mädchen und Frauen in der Ausbildung isc praktisch heute weirgehend beseitigt, wenn man die Examensergebnisse zum Indikator nimmt. Die Ungleichbehandlung im Arbeitsleben ist zwar immer noch drascisch, wird aber mir und olme Quore wirksam artackiert. Dic paritätische, komplementäre Aufgabcnceilung macht Fortschricte, wenn man etwa die soziale Kompetenz junger Männer im Abstand je eines Jahrzehnts vergleicht, obwohl trotz aller Modellvorstellungen in den (jüngeren) Parhaushalten die Frauen immer noch den Löwenanteil der Haushaltsaufgaben erledigen. Die Verringerung des Arbeirspotencials in den Industricgesellschaften aufgrund der elektronischen Revolution gibr aber dafür mir ihren kürzeren Arbeitszeiten einc bessere Chance zur Parität auch bei der Hausarbeit, wobei aber die Flexibilisienung der Arbentszeiten die gemeinsame Privatlebenszeit sogar zu verkürzen geeignet ist.

In der Paarbeziehung zeigt die allgemeine Erwartung inneren Verständnisses und seelischer Zuwcnóung ein vicl höheres Anspruchsniveau, als wir cs aus den historischen Formen der Bauern- und Bürgerfamilie kennen, aber auch noch aus den Jahrzehnren bis 1968 . In der nichtehelichen Lebensgemeinschaft beiderseits beruflich selbständiger Partncr, dic keinen institurionellen Zusanmenhalt suchen und die im Wissen um die Fragilität und Löslichkeit ihrer Bezichung zusammenbleiben, nicht nur für die Ausbildungsphase oder wcgen der Rente, kulminiert dicse Veranderung. In der Respekrierung verdichteter sozialer Verbindungen auch außerhalb der leiblichen Verwandischaft, z.B. in Adoptiv- und Pflegefamilien, aber auch bei gleichgeschlechtlichen Paaren, setzen sich ansatzweise neve Solidarformen durch, die dem Zug zur Isolierung des Einzelnen, zur extremen Individualisierung und zum Atomismus der konsumierenden Subjekte entgegengeserzt sind.

Dem Staat wird am Ende nichts anderes übrig bleiben, als Familiarität neu zu definieren und sie überall dort zu schützen, wo er sie vorfinder. Hier sind jeweils Entwicklungen fortzuschreiben, die sich auch in der Vergangenheit für den Gesetzgeber als unausweichlich dargestclit haben. Ohne vergleichbare Traditionslinie ist jedoch ein neuer Faktor des Familienreches, der mit den neuen Technologien der menschlichen Fortpflanzung verbunden ist. Homologe und hecerologe Inseminacion, In-vitro-Fertilisation, Ei-und Embryorransfer, Leilimutcerschaft und gar künfrig gentechnische Manipularionen sind die Stichworce eines Eingriffs in die ohnehin prekäre Familienordnung. An ihrem Anfang steht der bescheidene Wunsch unfruchtbarer Eltern oder Elternteile, die cin Kind aufziehen und lieben wollen. Im Hinblick auf Umweltbelastungen und psychischen Streß ist eine solche Unfruchtbarkcit heute auch kein absoluter Ausnahmefall. Der Geseizgeber näherc sich den Problem mir Vorschriften für Ärzte und Kliniken, während die familienrechrlichen Konsequenzen im neuen Abstammungsrecht nicht explizir geregelt sind. Eine ciefgrcifende Erschü:terung der gesamcen familiären Beziehungen könnte am Ende dieser Entwicklung stehen, wenn Konflikıe zwischen biologischen und sozialen Eltern verschiedener Provenienz zur Debacte stehen sollten. Mag sein, daß sich dann auch ein neuer Biologismus herausbildes, wie er teilweisc heute schon in Ansätzen crkennbar ist, so wenn das Bundesverfassungsgericht ein Recht aut Kenntnis der eigenen Abstarnmung olıne Rücksicht auf die gelebten Familienzusammenhange gewährt hat ${ }^{g 2}$.

Was also lernen aus der Geschichte des Familienreches in diesem Jahrluundert? Die Erkenntnis, wie langwierig es war, das Patriarchat aufgrund der Analysen des 19. Jahrhunderts in Schutt und Asche zu legen, bietet noch keine produktiven Ansätze. Die Unausweichlichkeit des eingeschlagenen Weges wird vor allem an der ungehcuren

92 Ganz uberzachend cingefulin durch BVerfG NJW/ $19 \$ 9,891$. 
Energie deutlich, mit der die christliche Verbrämung des Patriarchats verteidigt wurde. Daß der jeczige Rechrszustand, weitgehend auch geschaffen von einem christdemokratisch dominiereen Gesetzgeber, eigentlich eine Ausycburc des Sozialismus und des Individualismus ist, wenn man die Sichtwcise von 1900 , aber auch der langen joer Jahre zugrunde lcgt, wird diejenigen nicht urösten, die in den erscen zwei Dritteln des Jahrhunderts im Namen des Familienrechts dic bittersten Nicderlagen und Katastrophen hinzunehmen hatten. Erwiesen scheint, daß der Kapicalismus, dic Industriegesellschaft und das Computerzeitaiter den Patriarchalismus niche brauchen, ja womöglich, daß damir ein teilwcisc widerständiges Sozialsystem auf́gelöst ist. Das für eine Gesellschafo norwendige Minimum familiären Zusammenhalcs ist aber gleichfalls bedroht. Insofern können Arbcirslosigkeit und Familienlosigkeit auch eine Selbstaufhebungstendenz der kapicalistischen Wirtschaftsordnung bedcuren. Die gemessen an früheren Jahrzehncen - verhältrismäßig hohen Aufwendungen des Staates für Familien mic Kindern reichen nicht aus, um den mic Kindern verbundenen Einkommens- und Konsumverzicht aufzuwiegen. Die noch festcren familiären Zusammenhängc der eingewanderten Bevölkerungsteilc sind deswegen eine ganz entscheidende demographische Hoffnung. Aber auch bei ihnen zeicliner sich die Überforderung der Familie ab, im kulcurellen Gegensatz der erscen und der folgenden Einwanderergenerationen sogar mit besonderer Hefrigkeit. Wenn wir hcurc bei der Entschcidung von Familienkonfliken in den ausländischen Minderheiren dann immer wieder patriarchalischen Rechtsnormen ihres jeweiligen Heimatrechts begcgnen, die bei uns sclbst vor ciniger Zeit noch Bestand hatcen, solltc sich deswegen jede Überlegenheitsgeste verbieten. Es bedeutet auch keine letzte Reverenz an das $\mathrm{Pa}$ triarchat, wenn man den Einwandererfamilien hier nicho in der Scunde des Familiengerichtes die Akzeptanz für sämiliche Normen abverlange, für deren Bildung zwischen Rhein und Oder ein Jahrhundert benörigt wurde. 